\title{
SOURCES OF GLOBAL CLIMATE DATA AND VISUALIZATION PORTALS
}

\author{
DAVID C. DOUgLas \\ US Geological Survey, Alaska Science Center, 3100 National Park Road, \\ Juneau, AK 99801, USA. E-mail: ddouglas@usgs.gov
}

\begin{abstract}
Climate is integral to the geophysical foundation upon which ecosystems are structured. Knowledge about mechanistic linkages between the geophysical and biological environments is essential for understanding how global warming may reshape contemporary ecosystems and ecosystem services. Numerous global data sources spanning several decades are available that document key geophysical metrics such as temperature and precipitation, and metrics of primary biological production such as vegetation phenology and ocean phytoplankton. This paper provides an internet directory to portals for visualizing or servers for downloading many of the more commonly used global datasets, as well as a description of how to write simple computer code to efficiently retrieve these data. The data are broadly useful for quantifying relationships between climate, habitat availability, and lower-trophic-level habitat quality - especially in arctic regions where strong seasonality is accompanied by intrinsically high year-to-year variability. If defensible linkages between the geophysical (climate) and the biological environment can be established, general circulation model (GCM) projections of future climate conditions can be used to infer future biological responses. Robustness of this approach is, however, complicated by the number of direct, indirect, or interacting linkages involved. For example, response of a predator species to climate change will be influenced by the responses of its prey and competitors, and so forth throughout a trophic web. The complexities of ecological systems warrant sensible and parsimonious approaches for assessing and establishing the role of natural climate variability in order to substantiate inferences about the potential effects of global warming. Received 12 October 2011, accepted 28 October 2011.
\end{abstract}

Douglas, D. C. 2011. Sources of global climate data and visualization portals. Pages 101-116 in R. T. Watson, T. J. Cade, M. Fuller, G. Hunt, and E. Potapov (Eds.). Gyrfalcons and Ptarmigan in a Changing World, Volume I. The Peregrine Fund, Boise, Idaho, USA. http://dx.doi.org/ 10.4080/gpcw.2011.0110

Key words: climate data, reanalysis, weather, NDVI.

THE EARTH IS IN A CONSTANT STATE of thermal disequilibrium. Because the earth is rotating, and tilted on its axis, solar heating and cooling is not uniform across the planet. Terrestrial areas heat and cool faster than oceans, warm air rises, and cold water sinks. Interactions with geostrophic forcing, and benthic and terrestrial terrain, give rise to ocean currents and patterns of atmospheric circulation. Adding natural stochasticity renders the dynamics of 
weather-and extreme weather can have significant and often negative consequences on individuals, populations, and habitats.

Growing awareness of climate forcing by greenhouse gases (and black carbon) has fostered growing concerns about how climate change, and rates of change, may impact species and ecosystems. A growing number of biological studies now strive to better understand the sensitivity or resiliency of species and ecosystems to climate change. Projecting the effects of climate change, however, requires baseline knowledge about a species' or ecosystem's sensitivity to the natural climate variability within which it evolved. Hence there is a growing need for biologists and ecologists to integrate information about climate into their experimental designs and analytical frameworks.

Here I have documented several current sources of meteorological data that are global or continental in scale and freely available for scientific use. I focus on reanalysis data sets, not observational data. If a study can meet its objectives with data from observations (i.e., ground station, radiosonde, satellite, etc.), those data are likely superior to reanalysis data. For studies that span extensive or remote landscapes, however, reanalysis data can afford a systematic source of quasi-observational information that is continuous through time and space. I also document sources of vegetation greenness data derived from satellite imagery, such as the Normalized Difference Vegetation Index (NDVI), and similar vegetation proxies.

Like any documentation of this kind, internet addresses will become obsolete and better methods of data access and visualization will replace those described herein. As such, this report provides a present-day starting point to the expanding compilations of geophysical data worldwide, and to some of the rapidly developing tools for accessing and visualizing the data.

\section{Reanalysis Data Sets}

Reanalysis is a method that uses an extensive suite of observational data from many sources to inform a modeling process that produces a temporally and spatially continuous global (or regional) best estimate of numerous atmospheric, terrestrial and oceanographic parameters. Table 1 identifies five of the more commonly used reanalysis data sets, as well as a relatively new interpolated product for western Eurasia (Haylock et al. 2008) that contains continuous daily estimates of surface air temperature, precipitation, and pressure, from 1950 to present.

Reanalysis outputs include hundreds of variables describing temperature, precipitation, wind, pressure, and humidity - at the surface and at multiple levels in the atmosphere. Global reanalysis outputs have relatively coarse spatial resolution ( 2.5 degrees to 0.5 degrees) and high temporal resolution (1 to 6 hours). Regional reanalyses have higher spatial resolution. The global NCEP Reanalysis (Kalnay et al. 1996) spans 1948 to present and has been the most widely applied and published reanalysis data set. Many other reanalysis data sets (e.g., NCEP Reanalysis-2, ERA-Interim, and NASA Merra) span 1979 to present, a period for which the input data are significantly bolstered by satellite remote sensing.

To ascertain a representative sense of the types of output variables that comprise a reanalysis data set, a complete list from the North American Regional Reanalysis (NARR) is presently available: http://www.emc.ncep.noaa.gov/ $\mathrm{mmb} / \mathrm{rreanl} / \mathrm{merged}$ land_AWIP32.pdf

Similarly, a sense of the types of input data that are assimilated in reanalysis modeling can be ascertained from the European Centre for Medium-Range Weather Forecasts (ECMWF) website at: http://www.ecmwf.int/products/ forecasts/guide/ 
Table 1. Internet links to global and regional climate data sets, plotting portals, and OPeNDAP portals.

\begin{tabular}{|c|c|c|c|c|c|}
\hline & Reanalysis Dataset & Period & Spatial & Temporal & Domain \\
\hline 1 & \multicolumn{5}{|c|}{$\begin{array}{ll}\text { http://www.esrl.noaa.gov/psd/data/gridded/data.ncep.reanalysis.html } \\
\text { plotting portal: } & \text { http://www.esrl.noaa.gov/psd/cgi-bin/data/getpage.pl } \\
\text { plotting portal: } & \text { http://www.esrl.noaa.gov/psd/cgi-bin/db_search/SearchMenus.pl } \\
\text { OPeNDAP portal: } & \text { http://www.esrl.noaa.gov/psd/thredds/catalog/Datasets/catalog.html } \\
\text { OPeNDAP portal: } & \text { http://nomad3.ncep.noaa.gov/ncep_data/ }\end{array}$} \\
\hline 2 & NCEP/DOE Reanalysis-2 & 1979 - ongoing & 2.5 degree & 6 hour & global \\
\hline
\end{tabular}

http://www.esrl.noaa.gov/psd/data/gridded/data.ncep.reanalysis2.html

plotting portal:

OPENDAP portal:

http://www.esrl.noaa.gov/psd/cgi-bin/db_search/SearchMenus.pl OPeNDAP portal: http://www.esrl.noaa.gov/psd/thredds/catalog/Datasets/catalog.html http://nomad3.ncep.noaa.gov/ncep_data/

3 ECMWF ERA-Interim

http://data-portal.ecmwf.int/ registration for access to data: plotting portal:

Python or Perl extraction scripts:
1979 - ongoing
1.5 degree
6 hour
global

http://data-portal.ecmwf.int/data/d/license/interim/ http://climexp.knmi.nl/ http://data-portal.ecmwf.int/data/d/token/interim_daily/

4 NASA Merra

1979 - ongoing

$1 / 2 \times 2 / 3$ degree 1 hour

global

http://disc.sci.gsfc.nasa.gov/daac-bin/DataHoldings.pl

file specification doc:

plotting portal:

OPeNDAP portal (by variable):

OPeNDAP portal (by variable):

OPeNDAP portal (by day):

OPeNDAP portal (by day):

http://gmao.gsfc.nasa.gov/research/merra/file_specifications.php

http://disc.sci.gsfc.nasa.gov/giovanni/

http://goldsmr2.sci.gsfc.nasa.gov/dods/

http://goldsmr3.sci.gsfc.nasa.gov/dods/

http://goldsmr2.sci.gsfc.nasa.gov/opendap/

http://goldsmr3.sci.gsfc.nasa.gov/opendap/

5 North American

Reanalysis (NARR)

1979 - ongoing

0.1875 degree

3 hour

North

http://www.emc.ncep.noaa.gov/mmb/rreanl/

plotting portal:

OPeNDAP portal ${ }^{1}$ :

http://www.esrl.noaa.gov/psd/data/narr/\#plot

http://nomads.ncdc.noaa.gov/dods/

OPeNDAP portal ${ }^{2}$ :

OPeNDAP portal:

${ }^{1}$ Lat/Lon; ${ }^{2}$ Lambert projection

http://www.esrl.noaa.gov/psd/thredds/catalog/Datasets/catalog.html http://nomads.ncdc.noaa.gov/thredds/narr.html

6 European Interpolation
(E-OBS v5.0)
1950 - ongoing
0.25 degree
1 day
Western
http://eca.knml.nl (temperature, precipitation, and sea level pressure)
Eurasia

http://climexp.knmi.nl/ 
It may also be obtained from Dee et al. (2011) who provide a thorough description of the ERA-Interim product.

Online glossaries assist a basic understanding of the definitions and information content of the reanalysis output variables:

http://www.wrcc.dri.edu/ams/glossary.html http://www.crh.noaa.gov/dtx/afdterms.php http://weather.unisys.com/model/details.php

\section{Plotting Reanalysis Data}

For data exploration, the most convenient way to visualize reanalysis data is to use a webbased portal. Such portals allow a user to make customized, downloadable graphics directly from the data stored on an internet server. Many portals also provide useful analytical capabilities, such as regressions and correlations among other variables or climate indices. Links to several visualization portals are provided in Table 1, and several examples of graphics created with the portals are presented in Appendix A (Figures A1-A9).

The Open-source Project for a Network Data Access Protocol (OPeNDAP) has given rise to a rapidly growing number of servers and software that facilitate data access across the internet. The OPeNDAP protocol may well become the most widely-used method of serving geophysical data in the coming decade. The precursor to OPeNDAP was DODS (Distributed Oceanographic Data Server). Meteorologists have endorsed the efficacy of OPeNDAP, and numerous institutions are serving reanalysis data, weather observations, weather forecasts, and climate projections. While this paper focuses on terrestrial and atmospheric data, internet access to comprehensive oceanographic data sets can be obtained at: http://coastwatch.pfeg.noaa.gov/erddap/ http://icoads.noaa.gov/

A variety of software packages have been developed that can subset, analyze, or plot data directly from OPeNDAP servers (see http://opendap.org/othersoftware). The Integrated Data Viewer (IDV, http://www.unidata. ucar.edu/software/idv/) is relatively easy and useful for plotting data from hundreds of OPeNDAP servers; although IDV does not subset or download raw data. The Gridded Analysis and Display System (GrADS) is probably the most flexible and widely used software (http://grads.iges.org/grads/grads. html), albeit with a steeper learning curve.

\section{SubSetting Reanalysis Data}

The total volume of data comprising a full reanalysis is intractable for most users to practically consider downloading. For example, the current complete NARR data set is roughly 29.4 Tbytes. Most users need but a few specific variables, and perhaps only a limited geographic extent or time period. The most efficient method to download subsets of reanalysis data depend on users' needs and capabilities of the data server. There is no single, uniform method that best meets every need. Rather, a user should study documentation at the server website to learn about various subsetting options that have been made available for this common task.

Many of the plotting portals, particularly NCEP (Table 1), provide an option to download the subset of raw data that was used to generate the plot itself. This option provides an indirect method to acquire a subset - by first constructing a graphic that is based on the raw data of interest.

Other methods to access reanalysis data capitalize on a broad and active community of developers that are providing custom packages and functions that run under open-source software such as R (http://www.r-project.org/) and Python (http://www.python.org/). For Python users, the Pydap library (http://pydap.org/) implements data access protocols (see OPeNDAP below) to hundreds of scientific datasets on the internet. For R users, the RNCEP 
library (Kemp et al. 2011, http://sites.google. $\mathrm{com} / \mathrm{site} / \mathrm{michaelukemp/rncep)} \mathrm{retrieves} \mathrm{data}$ from the NCEP Reanalysis and Reanalysis-2 for specified areas and time periods, and provides functions for aggregating and graphing the data.

The NCEP, NARR, and Merra reanalysis data servers currently support OPeNDAP queries (Table 1). A user guide for this general method and several types of OPeNDAP messaging services is presently hosted at: http://docs. opendap.org/index.php/UserGuideOPeNDAP Messages

One type of message service employs a simple http-query to request data subsets, which can be returned in ASCII format. The generalized syntax of this query is:

http://<server address $>/<$ dataset name $>$.ascii? $<$ variable $>$ [time][level][lat][lon]

Data on the server are organized in a multidimensional array, and the [time][level][lat][lon] fields define the specific array elements, the data for which will be returned in ASCII format. It is then incumbent on the user to ingest the ASCII data into software of their choosing for subsequent analysis. A clear understanding of the array structure of the raw data is necessary to correctly prescribe the [time][level] [lat][lon] fields such that the desired data are returned. Appendix B exemplifies how to construct an OPeNDAP http-query to acquire a very specific subset of reanalysis data.

\section{Vegetation Greenness (NDVI) Data Sets}

Numerous studies have used the Normalized Difference Vegetation Index (NDVI) as a proxy to estimate vegetation biomass and vegetation phenology and its influence on animal ecology (Pettorelli et al. 2005, 2011). Any quantitative application of NDVI time series data warrants careful consideration of the subtle but important differences among the satellite sensors and the data processing methods pertaining to the various long term records of NDVI (Alcaraz-Segura et al. 2009, 2010, de Jong et al. 2011).

Clear sky conditions are required to obtain reliable NDVI measurements, and while maximum NDVI compositing methods reduce contamination (notably clouds), most NDVI time series require additional smoothing to exclude noise (Hird and McDermid 2008). The software TIMESAT (http://www.nateko.lu.se/ TIMESAT/) is a convenient and fairly popular tool for smoothing NDVI time series.

Recent or commonly used compilations of NDVI data are listed in Table 2 with internet links for obtaining the data. The most recent and sophisticated compilation of long-term NDVI data is the NASA MEaSUREs project (Table 2.1) which bridges continuity between the AVHRR and MODIS sensors. Users should be cognizant, however, that the MEaSUREs 'gap-filled' product, as well as the GIMMS-G product, substitute long-term NDVI averages for 'missing data', which for some analytical objectives can introduce undesirable NDVI commission errors.

Relationships between precipitation and NDVI during early summer in an arid grassland/scrubland in southern Idaho, USA, are illustrated in Figures A10 and A11. Variations in plant growth (NDVI) in arid habitats are typically linked to precipitation, while temperature is a more dominant factor controlling growth at high latitudes and high elevations. Because vegetation is the foundation of terrestrial food chains, quantifying its response to variations in weather patterns at landscape scale provides important insights into how climate change could affect ecosystems. Establishing linkages between variations in vegetation phenology and the demographics of animal populations (e.g., Figure A12) is more challenging, but a central topic for future research. Most (if not all) studies of this type are limited to establishing relationships through correlation, so caution should be exercised to 1) use conservative Type 1 error protection; 2 ) dis- 
Table 2. Internet links to global and regional NDVI data sets.

\begin{tabular}{|c|c|c|c|c|c|}
\hline & NDVI Dataset & Period & Spatial & Temporal & Domain \\
\hline \multirow[t]{2}{*}{1} & $\begin{array}{l}\text { NASA MEaSURES } \\
\text { (AVHRR \& MODIS) }\end{array}$ & 1982 - ongoing & 0.05 degree & $\begin{array}{l}\text { daily, twice } \\
\text { monthly }\end{array}$ & global \\
\hline & \multicolumn{5}{|c|}{$\begin{array}{l}\text { https://community.eosdis.nasa.gov/measures/vegetation.html } \\
\text { data: http://measures.arizona.edu/viplab_data_explorer.php }\end{array}$} \\
\hline \multirow[t]{2}{*}{2} & NASA GIMMS (AVHRR) & $1981-2006$ & $8 \mathrm{~km}$ & Twice monthly & global \\
\hline & \multicolumn{5}{|c|}{$\begin{array}{l}\text { http://glcf.umiacs.umd.edu/data/ } \\
\text { data: ftp://ftp.glcf.umd.edu/glcf/GIMMS/ }\end{array}$} \\
\hline \multirow[t]{2}{*}{3} & LTDR V3 (AVHRR) & $1981-1999$ & 0.05 degree & daily & global \\
\hline & \multicolumn{5}{|c|}{$\begin{array}{l}\text { http://ltdr.nascom.nasa.gov/cgi-bin/ltdr/ltdrPage.cgi } \\
\text { data: ftp://ltdr.nascom.nasa.gov/Ver3/ }\end{array}$} \\
\hline \multirow[t]{2}{*}{4} & USGS 1KM (AVHRR) & 1989 - ongoing & 1000 m & 7 and 14 day & CONUS \& Alaska \\
\hline & \multicolumn{5}{|c|}{$\begin{array}{l}\text { http://phenology.cr.usgs.gov/ndvi_avhrr.php } \\
\text { data: http://earthexplorer.usgs.gov }\end{array}$} \\
\hline \multirow[t]{2}{*}{5} & SPOT Vegetation & 1999 - ongoing & $1150 \mathrm{~m}$ & 10 day & global \\
\hline & \multicolumn{5}{|c|}{$\begin{array}{l}\text { http://www.spot-vegetation.com/ } \\
\text { data: http://free.vgt.vito.be/ }\end{array}$} \\
\hline \multirow[t]{2}{*}{6} & MODIS & 2000 - ongoing & $\begin{array}{l}250,500, \text { and } \\
1000 \mathrm{~m}\end{array}$ & 16 day & global \\
\hline & \multicolumn{5}{|c|}{$\begin{array}{l}\text { http://modis-land.gsfc.nasa.gov/ } \\
\text { data: https://lpdaac.usgs.gov//pdaac/products/modis_products_table } \\
\text { data (global subsets): http://daac.ornl.gov/cgi-bin/MODIS/GLBVIZ_1_GIb/modis_subset_order_global_col5.p } \\
\text { data (North America): http://accweb.nascom.nasa.gov/data/ }\end{array}$} \\
\hline 7 & USGS e-MODIS & 2000 - ongoing & $\begin{array}{l}250,500, \text { and } \\
1000 \mathrm{~m}\end{array}$ & 1 and 2 week & CONUS, Alaska, others \\
\hline & $\begin{array}{l}\text { http://pubs.usgs.gov/of/2 } \\
\text { data: http://dds.cr.usgs.g }\end{array}$ & $\begin{array}{l}2010 / 1055 / \\
\text { gov/emodis/ }\end{array}$ & & & \\
\hline
\end{tabular}

miss alternative explanations; and 3) provide plausible mechanistic interpretations.

\section{Conclusions}

As a basis from which to project the effects of climate change, many biologists are striving to better understand how contemporary climate affects the quality of habitats and the reproductive fitness of plants and animals (and agricultural systems). Concurrently, sources of climate data are rapidly expanding, as are data visualization portals and software utilities. This report provides a directory to several of the more commonly used reanalysis data sets, data visualization portals, and NDVI time series.

\section{ACKNOWLEDGMENTS}

NCEP and NARR Reanalysis data provided by the NOAA/OAR/ESRL PSD, Boulder, Colorado, USA, from their Web site at http://www.esrl.noaa.gov/psd/. ERA-Interim reanalysis data provided by the ECMWF from their website at http://data-portal.ecmwf.int/. The NASA Merra reanalysis data provided by the Goddard Earth Sciences Data and Information Services Center. The Giovanni online data 
system was developed and is maintained by the NASA GES DISC. The E-OBS dataset was from the EU-FP6 project ENSEMBLES (http://ensembles-eu.metoffice.com) and data providers in the ECA\&D project (http://eca. knmi.nl). NDVI data were kindly provided by the Global Inventory Modeling and Mapping Studies Group at NASA GSFC, the Long Term Data Record portal hosted at NASA GSFC, and the NASA LP DAAC. A. Fischbach and $M$. Rehberg provided reviews that added relevant content and clarity to this paper.

\section{Appendix A.}

Figures illustrating various reanalysis data sets and internet portals for making customized plots of selected variables, time periods, and regions.
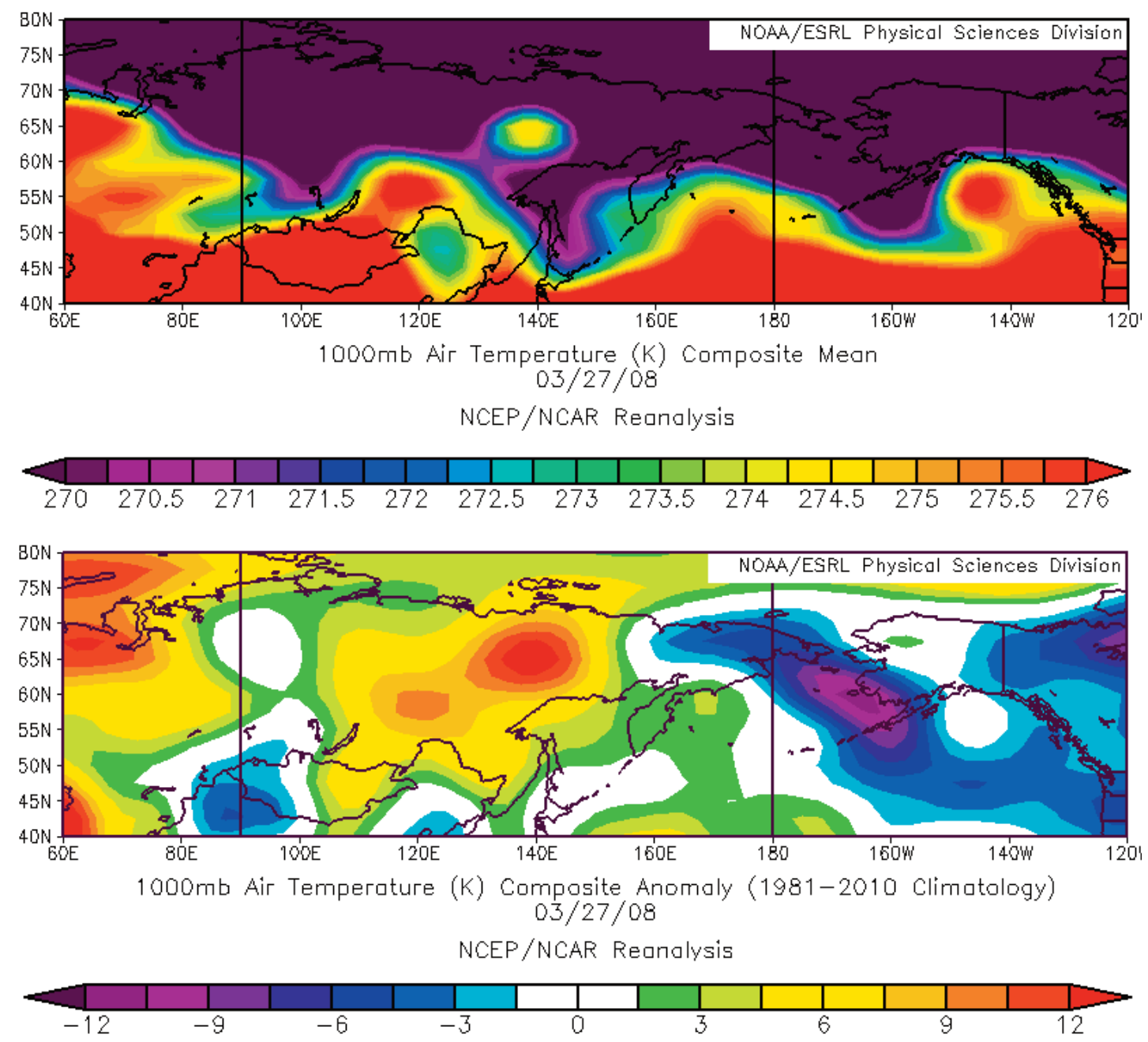

Figure A1. Near surface (1000 mb) air temperature across eastern Eurasia and northwestern North America on March 27, 2008. Temperature is shown as the daily average (top), and as departure from a long-term average (bottom). A late-winter thaw event is evident in the Sakha Republic sector of Russia. Data are from the daily NCEP Reanalysis and graphics from the NOAA/ESRL (Table 1.1). 
Figure A2. Average (1949-2010) April winds at $925 \mathrm{mb}$ ( $750 \mathrm{~m}$ altitude) across North and South America. Data are from the monthly NCEP Reanalysis and graphics from the NOAA/ESRL (Table 1.1).

NCEP/NCAR Reanalysis $925 \mathrm{mb}$ Vector Wind ( $\mathrm{m} / \mathrm{s}$ ) Composite Mean
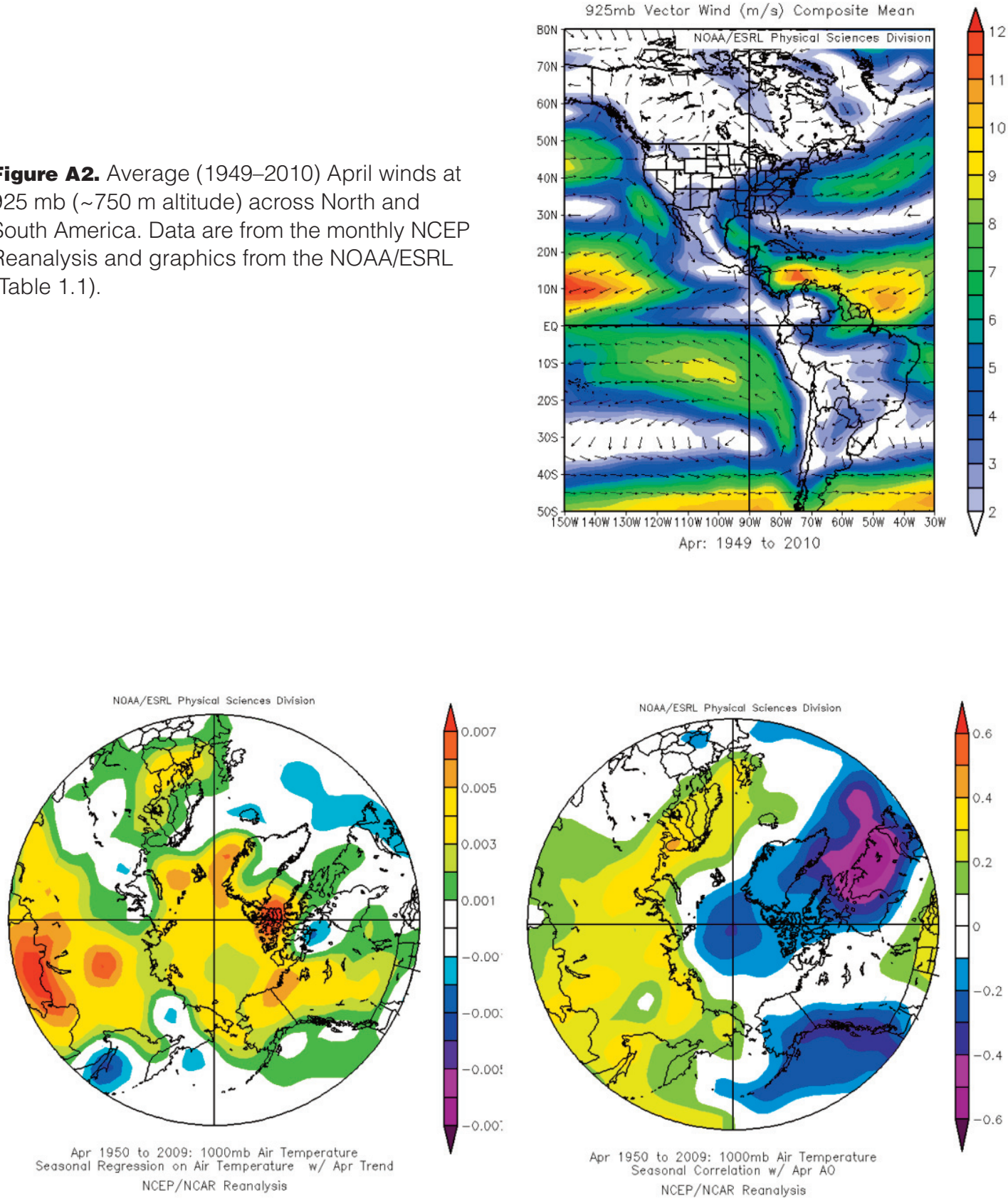

Figure A3. Linear trend in northern latitude $1000 \mathrm{mb}$ air temperature (left) and correlation between $1000 \mathrm{mb}$ air temperature and the Arctic Oscillation (AO) Index (right) during April, 1950-2009. April warming trends in near surface air temperature (over the 60-year period) are most pronounced in northern Mongolia, central Siberia, and northern Baffin Bay, Canada. In general, April near surface air temperature in northern latitudes tends to be inversely correlated with the April AO in the western hemisphere and positively correlated in the eastern hemisphere. Data are from the monthly NCEP Reanalysis and graphics from the NOAA/ESRL (Table 1.1). 

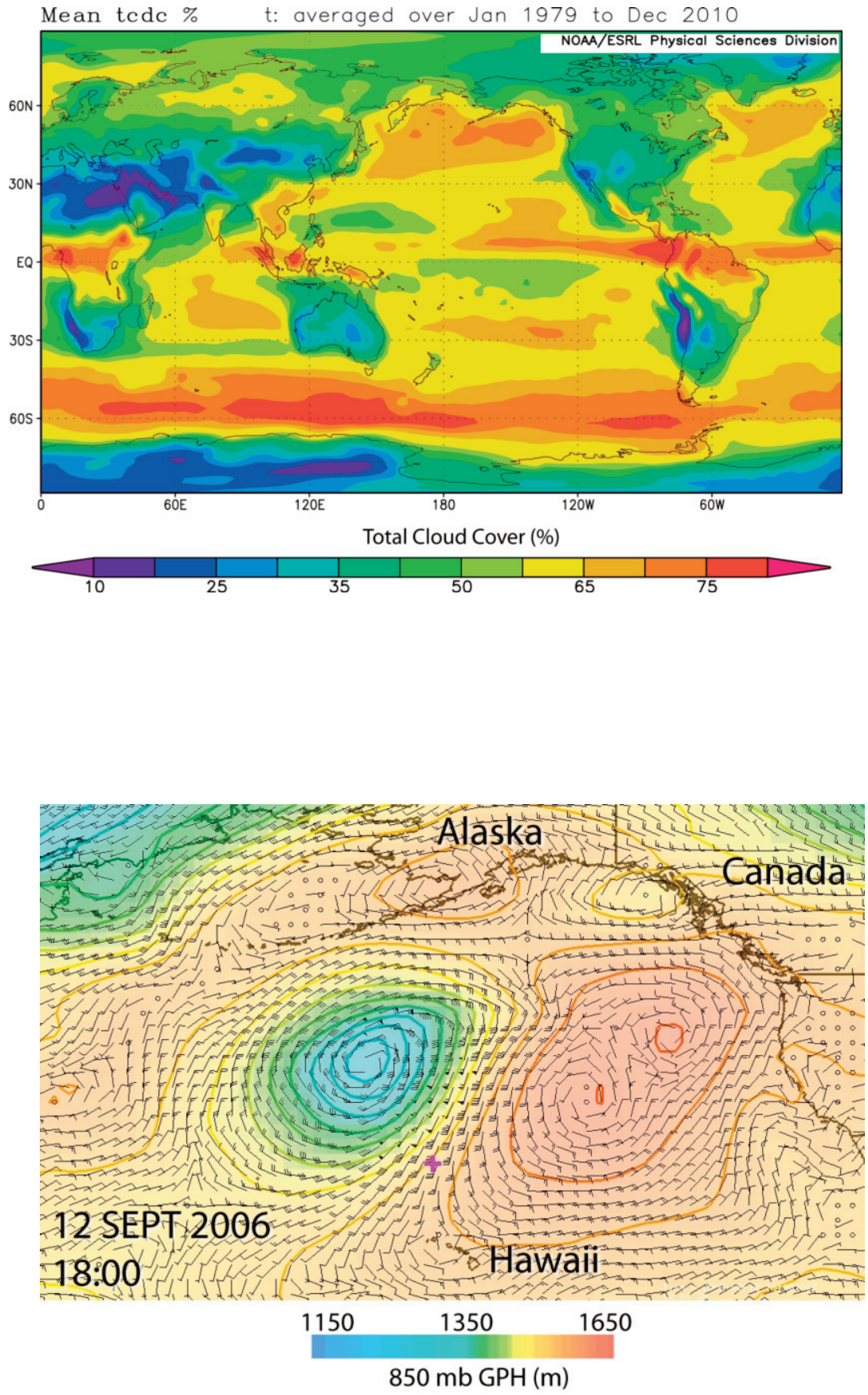

$850 \mathrm{mb}$ GPH $(\mathrm{m})$
Figure A4. Mean annual (January-December) total cloud cover during 1979-2010. Oceans generally tend to be cloudier than continents; cloud cover is high over terrestrial equatorial regions and low along the western coasts of southern Africa and central South America. Data are from the monthly NCEP Reanalysis-2 and graphics from the NOAA/ESRL (Table 1.2).
Figure A5. Wind (barbs) and geopotential height (color shading) at $850 \mathrm{mb}$ ( 1000 m altitude) over the north Pacific on September 12, 2006 at 18:00 GMT. Juxtaposition of low and high pressure cells over the north Pacific can generate troughs of strong winds that can impose challenges for shorebirds migrating from Alaska to the south Pacific in autumn. Weather data were downloaded from the ERA-Interim Reanalysis server (Table 1.3) in GRIB (GRIdded Binary) format, and then plotted using the Integrated Data Viewer (IDV) software package (http://www.unidata.ucar. edu/software/idv/). 
Figure A6. Total surface precipitation flux on the northeastern seaboard of the United States during landfall of Hurricane Irene, August 27-28, 2011. Data are from the NASA Merra reanalysis, and plotted with the Giovanni visualization portal developed and maintained by the NASA GES DISC (Table 1.4).
Figure A7. Geopotential height (850 mb) over North America on October 25, 2010, 12:00 GMT (top) and concurrent winds over southeastern United States (bottom). Juxtaposition of a deep low pressure cell over north central US and a high pressure system off the Atlantic coast promoted strong northwesterly winds over the southeastern states that spawned several tornadoes on this particular date. Data are from the North American Regional Reanalysis (NARR, Table 1.5); top panel illustrates the full spatial domain of the NARR data.
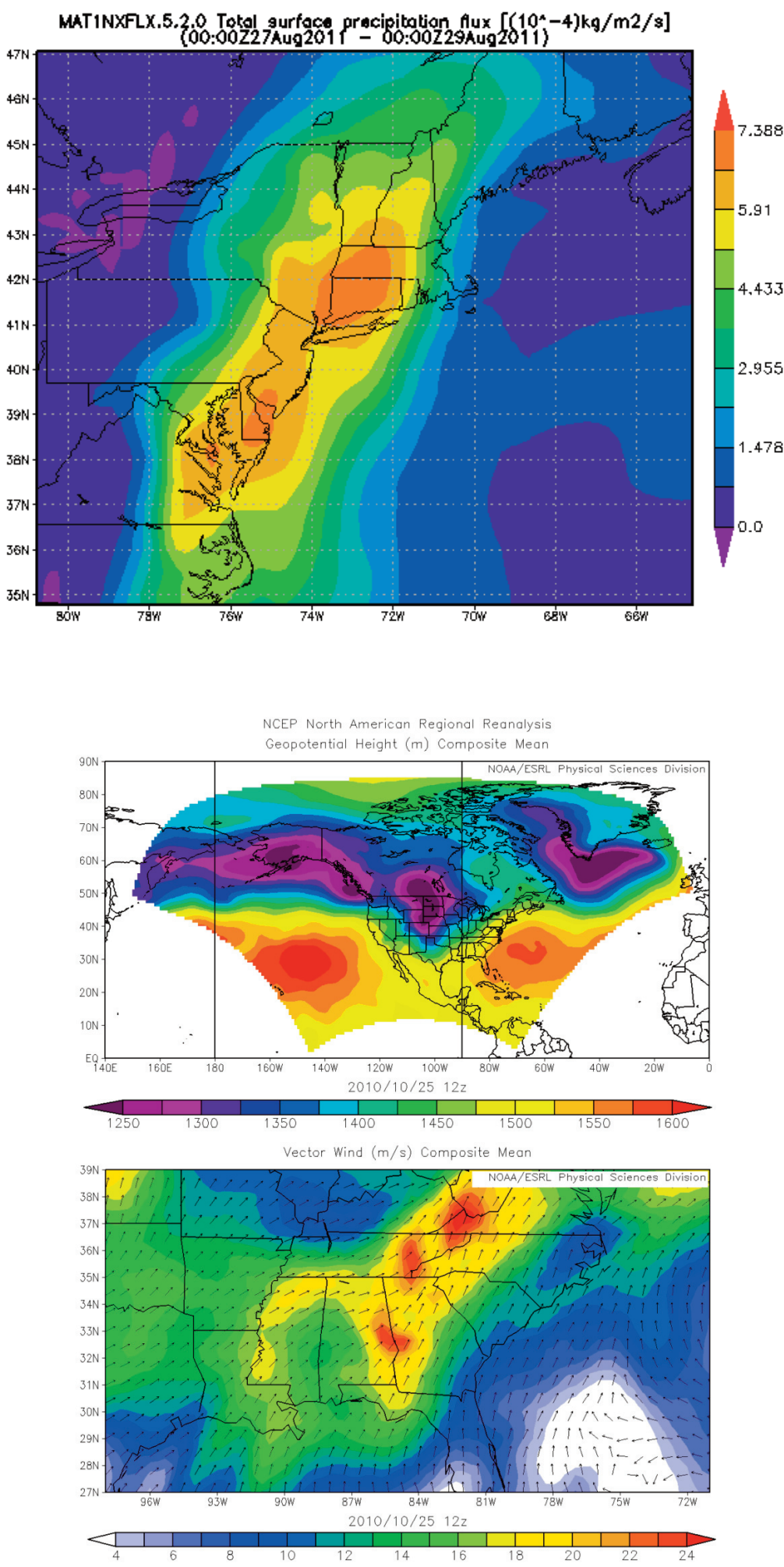


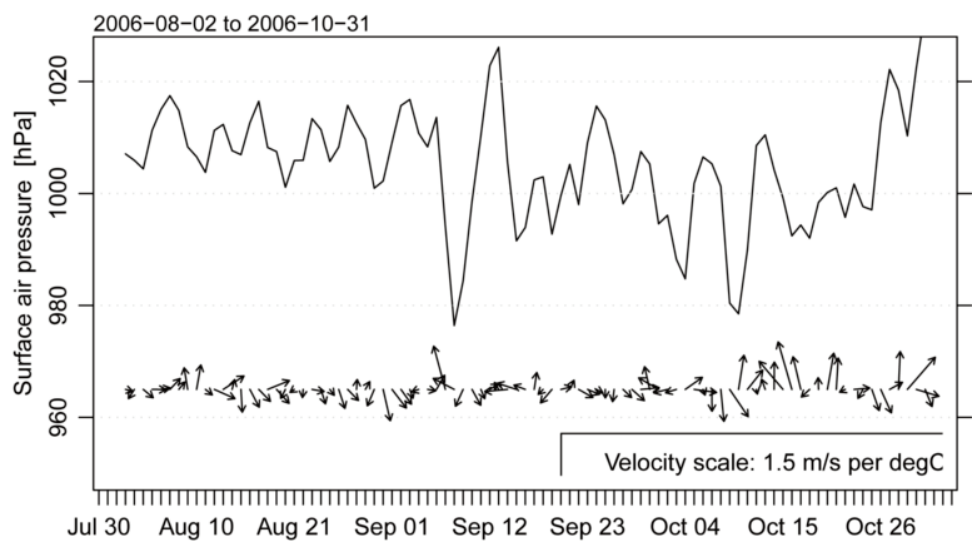

Figure A8. Time series of average daily surface air pressure (solid line) and $10 \mathrm{~m}$ elevation wind speed and direction (stick plots) on the southwestern coast of the Yukon-Kuskokwim Delta, Alaska, during August October, 2006. Avian species staging on the Delta in autumn often time their departure on southward migration to coincide with favorable winds, which is largely dictated by position of the Aleutian Low. Data are from the 3-hour NARR (Table 1.5), obtained in ASCII format using OPeNDAP protocols, reformatted and averaged within day, and plotted using Program-R functions 'oce.plot.ts' and 'oce.plot.sticks' from the R-library 'oce'.

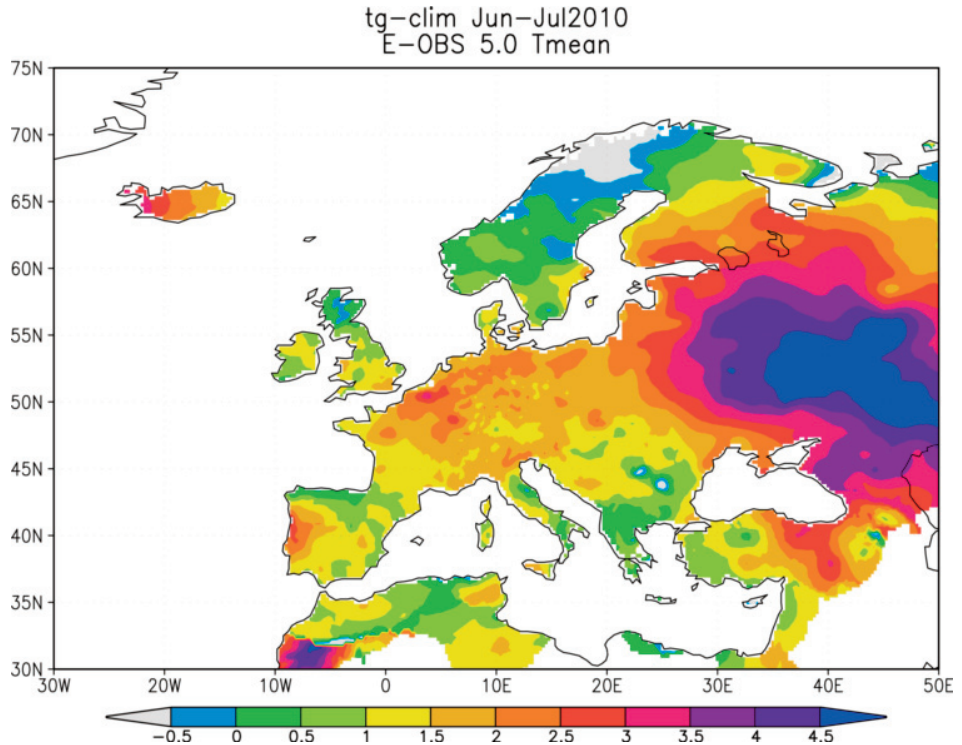

Figure A9. Average surface air temperature anomalies over western Eurasia during a record-breaking heat wave in June-July, 2010. Data are from the E-OBS time series, mapped with the KNMI Climate Explorer (Table 1.6). The map extent illustrates the full spatial domain of the EOBS data set. 
Figure A10. Annual anomalies in June vegetation greenness (NDVI) and May and June precipitation in western Owyhee County, Idaho. Condition of spring and early summer vegetation in this desert region is highly dependent on precipitation. Except for 2005, recent springs have been drier than average with less green vegetation in June. Detection of vegetation greenness in June 1992 was suppressed by high concentrations of atmospheric aerosols from the eruption of Mount Pinatubo. Precipitation data are from the North American Reanalysis (Table 1.5), obtained with OPeNDAP protocol. NDVI data are a synthesis of products (by the author) from NASA GIMMS (Table 2.3), LTDR (Table 2.3), and MODIS (Table 2.6).

Figure A11. Response of June vegetation greenness to May-June precipitation in western Owyhee County, Idaho, 1982 - 2008. Data were adapted from those shown in Figure A10.

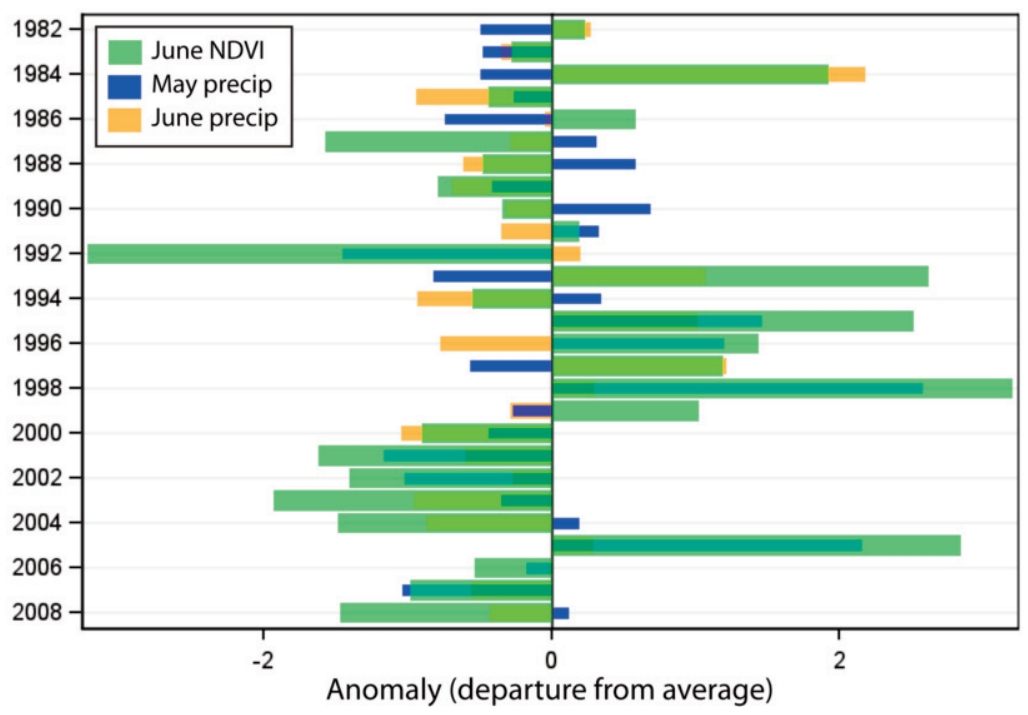

Anomaly (departure from average) 


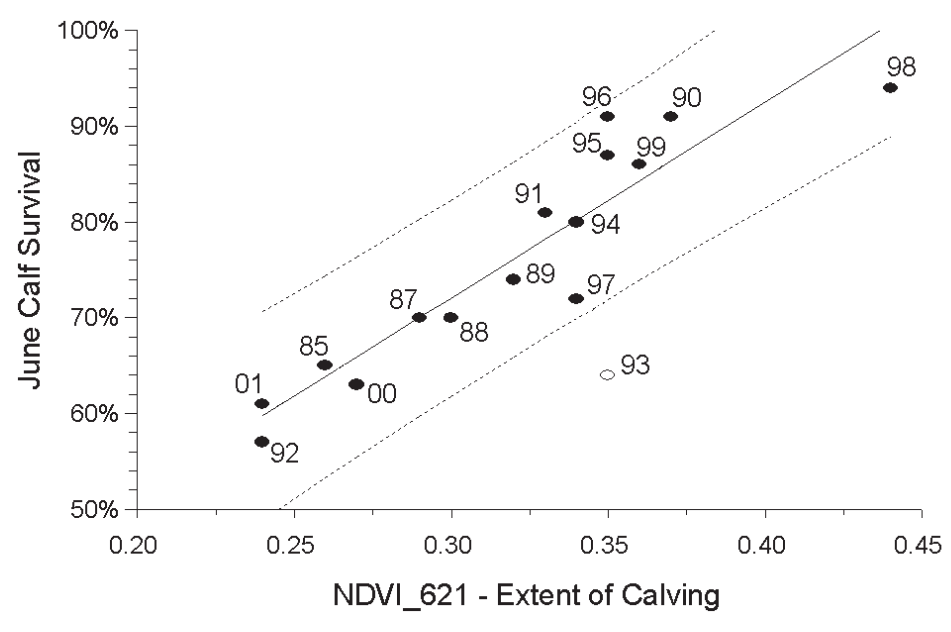

Figure A12. Calf survival through June for the Porcupine Caribou herd, 1985-2001, in relation to median Normalized Difference Vegetation Index on 21 June (NDVI_621) within the aggregate extent of calving. Figure from Griffith et al. (2002). 


\section{APPENDiX B.}

Example of constructing an OPENDAP http-query to acquire subsets of reanalysis data.

The OPENDAP http-query to request subsets of reanalysis data in ASCII format has the general syntax:http://<server address $>/<$ dataset name $>$.ascii? $<$ variable $>$ [time][level][lat][lon]

The [time][level][lat][lon] fields define the specific array elements for which the contents will be returned in ASCII format. The 'level' dimension only applies to data that span multiple levels (3D), typically atmospheric variables. For surface data, the 'level' dimension is omitted.

As an example, I apply this method to acquire $1000 \mathrm{mb}$ air temperature data from the NCEP Reanalysis during the warm anomaly over central Siberia on 27 March 2008, which is plotted in Figure A1. The target location of interest will be 64.4 N, 137.9 E. The first step is to navigate to an OPENDAP web address from Table 1, for example:

http://www.esrl.noaa.gov/psd/thredds/catalog/Datasets/catalog.html

In this case, follow the 'ncep.reanalysis' link, then the 'pressure' link, then 'air.2008.nc', then choose the "OPENDAP" link, and a "Data URL" will be displayed. This is the "http://<server address $>/<$ dataset name $>$ ' portion of the general syntax. To obtain information about the array structure of this data set, direct a web browser to the "Data URL" - suffixed with ".info" (some OPENDAP servers conveniently display an "info" link):

http://www.esrl.noaa.gov/psd/thredds/dodsC/Datasets/ncep.reanalysis/pressure/air.2008.nc.info

Study this information carefully. Note the variable name is 'air' and its units are degrees $\mathrm{K}$, and that the raw values need to be offset by 477.66 and scaled by 0.01 . Note the time, level, lat, and lon array dimensions, which are 0-1463, 0-16, 0-72, and 0-143, respectively. The time dimension has 1464 array elements, which is 366 days (2008 is a leap year) $\mathrm{x}$ four 6-h periods per day (00:00, 06:00, 12:00, and 18:00). Time begins 01 Januray 2008 at 00:00 and increments by $6 \mathrm{~h}$ intervals; latitude begins at +90 degrees and increments by -2.5 degree intervals; and longitude begins at 0 degrees and increments by 2.5 degree intervals.

The period of interest is 27 March (Julian day 87) which equates to four 6-hour elements in the time array, specifically the array elements: 344-347. There are 17 (0-16) elements in the level array; levels are defined as geopotential heights. The level ' $1000 \mathrm{mb}$ ' (near surface) is element 0 in this array. The latitude of interest is $64.4 \mathrm{~N}$ is bounded by two latitude array elements (10 and 11 ); and the longitude of interest is $137.9 \mathrm{E}$ is bounded by two longitude array elements (55 and 56). Thus, a complete http query for this example is: 
http://www.esrl.noaa.gov/psd/thredds/dodsC/Datasets/ncep.reanalysis/pressure/air.2008.nc.ascii? $\operatorname{air}[344: 347][0: 0][10: 11][55: 56]$

Submitting the URL above to a web browser will return the $1000 \mathrm{mb}$ air temperatures for 27 March 2008, at four times and at four 2.5-degree grid coordinates. Offsetting and scaling the raw values to attain degrees $\mathrm{K}$, and converting to degrees $\mathrm{C}$ yields the values shown below in bold font.

$\begin{array}{rccll}\text { GMT hour } & \text { Ion[0] 137.5 } \mathrm{I} & \text { Ion[1] 140.0 E } & \text { lat } & \\ \text { 0:00 } & \mathbf{1 . 0 5} & \mathbf{1 . 1 5} & 65.0 & \text { lat[0] } \\ \text { 0:00 } & \mathbf{0 . 5 5} & \mathbf{0 . 3 5} & 62.5 & \text { lat[1] } \\ \text { 6:00 } & \mathbf{3 . 9 5} & \mathbf{4 . 2 5} & 65.0 & \text { lat[0] } \\ \text { 6:00 } & \mathbf{4 . 0 5} & \mathbf{4 . 3 5} & 62.5 & \text { lat[1] } \\ \text { 12:00 } & \mathbf{2 . 8 5} & \mathbf{2 . 5 5} & 65.0 & \text { lat[0] } \\ \text { 12:00 } & \mathbf{2 . 1 5} & \mathbf{2 . 0 5} & 62.5 & \text { lat[1] } \\ \text { 18:00 } & \mathbf{- 1 . 4 5} & \mathbf{- 1 . 7 5} & 65.0 & \text { lat[0] } \\ \text { 18:00 } & \mathbf{- 2 . 8 5} & \mathbf{- 2 . 9 5} & 62.5 & \text { lat[1] }\end{array}$

Variants of the http query (above) are easily modified to return different variants of the air temperature data. For example, the entire $20081000 \mathrm{mb}$ temperature time series for a single grid location $(65.0 \mathrm{~N} 137.5 \mathrm{E})$ :

http://www.esrl.noaa.gov/psd/thredds/dodsC/Datasets/ncep.reanalysis/pressure/air.2008.nc.ascii? air[0:1463][0:0][10:10][55:55]

As above, but only for the 06:00 h temperature data. Note the time dimension syntax begins at element 1 (06:00) and includes a skip-factor of 4:

http://www.esrl.noaa.gov/psd/thredds/dodsC/Datasets/ncep.reanalysis/pressure/air.2008.nc.ascii? air[1:4:1463][0:0][10:10][55:55]

As above, but for the year 2009; note that total length of the time dimension is 4 less because 2009 is not a leap year:

http://www.esrl.noaa.gov/psd/thredds/dodsC/Datasets/ncep.reanalysis/pressure/air.2009.nc.ascii? $\operatorname{air}[1: 4: 1459][0: 0][10: 10][55: 55]$

Obtaining a 63-year (1948-2010) temperature record entails repeating the query above 63 times, once for each respective year. It is typically inconvenient, however, to have data returned to a browser window. To this end, the software utility 'wget' (http://gnuwin32.sourceforge.net/packages/wget.htm) can be used in a scripted or batch environment to redirect the results to a disk file: wget $<$ http-query $>-O$ - local-file $>$. Program R or Python users can accomplish wget functionality through the R library 'base' or Python library 'urllib'. 


\section{Literature Cited}

Alcaraz-Segura, D., E. Chuvieco, H. E. Epstein, E. S. KasischKe, AND A. TRISHCHENKO. 2009. Debating the greening vs. browning of the North American boreal forest: Differences between satellite datasets. Global Change Biology 16:760-770.

Alcaraz-Segura, D., E. Liras, S. Tabik, J. PARUelo, AND J. CABello. 2010. Evaluating the consistency of the 1982-1999 NDVI trends in the Iberian Peninsula across four time-series derived from the AVHRR Sensor: LTDR, GIMMS, FASIR, and PAL-II. Sensors 10:1291-1314.

DE Jong, R., S. DE Bruin, A. DE Wit, M. E. Schaepman, AND D. L. Dent. 2011. Analysis of monotonic greening and browning trends from global NDVI time-series. Remote Sensing of Environment 115:692702.

DeE, D. P., AND COAuthors. 2011. The ERAInterim reanalysis: Configuration and performance of the data assimilation system. Quarterly Journal of the Royal Meteorological Society 137:553-597.

Griffith, B., D. C. Douglas, N. E. Walsh, D. D. Young, T. R. MCCABe, D. E. Russell, R. G. White, R. D. CAMERon, And K. R. WhitTen. 2002. The Porcupine caribou herd. Pages 8-37 in D. C. Douglas, P. E. Reynolds, and E. B. Rhode (Eds.). Arctic Refuge Coastal Plain Terrestrial Wildlife Research Summaries. US Geological Survey, Biological Resources Division, Bio- logical Science Report USGS/BRD/BSR2002-0001, Reston, Virginia, USA.

HAYLOCK, M. R., N. HofsTRA, A. M. G. KleIN TANK, E. J. KloK, P. D. Jones, and M. NEW. 2008. A European daily high-resolution gridded dataset of surface temperature and precipitation. Journal of Geophysical Research (Atmospheres) 113, D20119. http://dx.doi.org/10.1029/2008JD10201

HiRD, J., AND G. J. MCDERMID. 2008. Noise reduction of NDVI time series: An empirical comparison of selected techniques. Remote Sensing of Environment 113:248258.

Kalnay, E., AND COAUTHORS. 1996. The NCEP/NCAR 40-year reanalysis project. Bulletin of the American Meteorological Society 77:437-471.

Kemp, M. U., E. E. van Loon, J. ShamounBARANES, AND W. BOUTEN. 2011. RNCEP: Global weather and climate data at your fingertips. Methods in Ecology and Evolution. http://dx.doi.org/10.1111/j.2041210X.2011.00138.X

Pettorelli, N., S. Ryan, T. Mueller, N. BunNEFELD, B. JEDRZEJEWSKA, M. LIMA, AND K. KAUSRUD. 2011. The Normalized Difference Vegetation Index (NDVI): Unforeseen successes in animal ecology. Climate Research 46:15-27.

Pettorelli, N., J. O. Vik, A. Mysterud, J.-M. Gaillard, C. J. Tucker, AND N. C. STENSETH. 2005. Using the satellite-derived NDVI to assess ecological responses to environmental change. Trends in Ecology and Evolution 20:503-510. 